\title{
Associated Injuries Are Frequent and Severe Among Geriatric Patients With Zygomatico-Orbital Fractures
}

\author{
Miika Toivari, DDS, *Johanna Snäll, DDS, MD, PbD, $\dagger$ \\ Anna Liisa Suominen, DDS, PbD, MSc, $\ddagger$ Satu Apajalabti, DDS, PbD, $\S$ \\ Christian Lindqvist, MD, DDS, PhD, // and Hanna Thorén, MD, DDS, PhD
}

Purpose: Associated injuries (AIs) are hypothesized to be frequent in geriatric zygomatico-orbital (ZMO) fractures. The study aim was to determine the relation between ZMO fractures and AIs in geriatric patients compared with younger adult patients.

Patients and Methods: A retrospective case-and-control study was carried out on geriatric patients at least 65 years of age $(n=93)$ and younger adult patients 20 to 30 years of age $(n=68)$ diagnosed with pure unilateral ZMO fractures. The main exposure was age, the primary outcome was AI outside the face, and the secondary outcomes were type and severity of AI, ocular injuries, restriction of mandibular movement, and ZMO buttress asymmetry. The confounding variables were gender, trauma mechanism, type of ZMO fracture, and dislocation. Statistical analyses included $\chi^{2}$ tests, risk evaluation with $2 \times 2$ tables, and logistic regression analysis.

Results: AIs outside the face, and particularly brain injuries, were significantly more frequent in the geriatric group than in the control group $(P<.001)$. The significant predictors of AIs outside the face were fall from a height (66.7\%), motor vehicle accidents (66.7\%), and absence of ZMO dislocation $(59.5 \% ; P<.001)$. The adjusted risk of brain injury was 2.5 -fold in the absence of dislocation. The geriatric group had a more than 5-fold higher risk of brain injuries compared with the younger control group $(P=.003)$.

Conclusions: AIs in general, and particularly brain injuries, are frequent in geriatric ZMO fractures. Intracranial injuries should be ruled out, particularly in geriatric patients diagnosed with a non-dislocated ZMO fracture.

(C) 2018 American Association of Oral and Maxillofacial Surgeons

J Oral Maxillofac Surg 77:565-570, 2019

*Resident, Department of Oral and Maxillofacial Diseases, University of Helsinki and Helsinki University Hospital, Helsinki, Finland.

†Consultant, Department of Oral and Maxillofacial Diseases, University of Helsinki and Helsinki University Hospital, Helsinki, Finland.

$\ddagger$ Professor, Departments of Health, Functional Capacity, and Welfare and Environmental Health, National Institute for Health and Welfare, Helsinki and Kuopio; Department of Oral Public Health, Institute of Dentistry, University of Eastern Finland, Kuopio; Department of Oral and Maxillofacial Surgery, Kuopio University Hospital, Kuopio, Finland.

$\S$ Consultant, HUS Medical Imaging Center, Department of Radiology, University of Helsinki and Helsinki University Hospital, Helsinki, Finland.
\|Professor Emeritus, Department of Oral and Maxillofacial Diseases, University of Helsinki and Helsinki University Hospital, Helsinki, Finland.

๑Professor, Department of Oral and Maxillofacial Diseases, Institute of Dentistry, University of Turku and Turku University Hospital, Turku, Finland.

Conflict of Interest Disclosures: None of the authors have any relevant financial relationship(s) with a commercial interest.

Address correspondence and reprint requests to Dr Toivari: Haartmaninkatu 4E, PL 220, 00029 HUS, Helsinki, Finland; e-mail: miika.toivari@helsinki.fi Received August 292018 Accepted October 212018 (c) 2018 American Association of Oral and Maxillofacial Surgeons 0278-2391/18/31199-6 
Zygomatico-orbital (ZMO) fractures are frequent. In a 2012 multicenter study, ZMO fractures were identified as the second most common type of facial injury $(24.0 \%)$ in European populations. ${ }^{1}$ In publications focusing on ZMO fractures needing surgical intervention, such fractures are most frequently reported in younger adult patients (20 to 50 years old; 58.6 to $76.1 \%$ ), and their injuries are commonly caused by assault (19.0 to $46.6 \%) .^{2-5}$ However, according to studies focusing on geriatric facial trauma, ZMO fractures also are among the most common facial fractures in the elderly (31.1 to $40.3 \%$ ).

In addition to their high frequency, associated injuries (AIs) are frequent in patients diagnosed with facial fractures. The rate of intracranial injuries, in particular, increases with increasing age, ${ }^{8}$ and their frequency varies from 18.8 to $51.4 \% .{ }^{9,10}$ Of the different types of brain injury, an association between ZMO fractures and subdural hematomas (SDHs) has been identified in the literature, ${ }^{11}$ and brain injury frequencies of up to 61.0 to $67.0 \%$ have been reported in patients diagnosed with ZMO fractures. ${ }^{12,13}$ The literature has clearly focused on the need for surgical intervention in ZMO fractures, and the authors are not aware of comparative publications focusing on the relation between AIs and ZMO fractures in geriatric patients with facial trauma.

The purpose of the present study was to investigate AIs in geriatric patients with ZMO fractures. The specific aims were to clarify the occurrence of, risk factors for, and types of $\mathrm{AI}$ in geriatric patients with $\mathrm{ZMO}$ fractures and to compare the occurrence of and types of AI between geriatric patients and younger adult patients (controls). The hypotheses were that AIs are frequent and severe in geriatric patients and that they occur more frequently in geriatric patients than in younger adult patients.

\section{Patients and Methods}

\section{STUDY DESIGN}

To address the aims, a case-and-control study was designed and performed. The study included geriatric patients at least 65 years old and younger adult patients 20 to 30 years old (controls) who had been diagnosed with a unilateral ZMO fracture during the 7-year period from January 1, 2010 through December 31, 2016. The cutoff age for the geriatric group was set at 65 years to cover all potentially frail elderly patients. Patients with any other facial fracture, except an adjuvant fracture of the coronoid process, were excluded.

\section{STUDY VARIABLES}

The main exposure was age (ie, geriatric vs younger adult patients).
The primary outcome variable was AI outside the face (present vs absent). This was defined as any other major injury outside the facial region, excluding brain concussions, wounds, and other superficial soft tissue injuries. The precise AI sites were recorded and further classified according to the affected organ system: 1) brain, 2) neck (excluding cervical spine), 3) spine, 4) extremities, 5) chest, and 6 ) abdomen.

The secondary outcome variables were the severity of AI outside the face, ocular injuries (present vs absent), restricted mandibular opening (present vs absent), and zygomatic prominence asymmetry (present vs absent). The severity of AI outside the face was classified as multiple AIs (ie, patients who had $\geq 2$ different AIs outside the face), polytrauma (involvement of $\geq 2$ organ systems and $\geq 1$ life-threatening injury), and mortality during hospitalization.

The predictor variables were gender, trauma mechanism, type of ZMO fracture, and ZMO fracture dislocation (present vs absent). The type of ZMO fracture was classified as 1) tripod ZMO fracture (consisting of the lateral orbit, inferior orbit, anterior and posterior maxillary wall, and zygomatic arch), 2) isolated arch fracture (consisting of only the zygomatic arch), and 3) ZMO fracture without arch involvement. The trauma mechanism was classified into 8 groups: 1) ground-level fall, 2) bicycle accident, 3) motor vehicle accident (MVA), 4) fall from height, 5) assault, 6) struck by a blunt object, 7) unknown, and 8) sportsrelated injuries.

\section{COMPUTED TOMOGRAPHIC ANALYSIS}

All patients underwent computed tomography (CT) using multidetector CT scanners (GE Healthcare, Milwaukee, WI) with a bone algorithm. The data were reformatted into 1.0-, 1.5-, or 2.0-mm-thick axial, coronal, and sagittal images. The CT images were retrospectively viewed independently by 2 of the authors (M.T. and S.A.). The features assessed included the type of ZMO fracture and presence or absence of dislocation. In the event of disagreement, a final diagnosis was reached by consensus reading.

\section{DATA ANALYSIS}

The $\chi^{2}$ tests were performed to examine the statistical relevance of the differences between the primary predictor (age group) and all other predictors and outcomes and between the main outcome and the predictors. Risk ratios with $95 \%$ confidential intervals (CIs) were calculated to examine the risk of outcome variables and the primary predictor. Logistic regression analysis was performed to study associations between the presence of brain injury and the primary predictor (age group), gender, and the absence of fracture 
dislocation and results were expressed as odds ratios and $95 \%$ CIs, separately and then adjusted for each other.

\section{ETHICAL CONSIDERATIONS}

The internal review board of the Division of Musculoskeletal Surgery of the Helsinki University Hospital (Helsinki, Finland) approved the study. Patient consent was not required because of the retrospective nature of the study.

\section{Results}

In total, 161 patients were identified for the present study (geriatric group, $n=93$; control group, $n=68$ ).

Table 1 presents the association between gender, trauma mechanism, type of ZMO fracture, presence of dislocation, and age group. Men were more frequent in the control group than in the geriatric group $(P<.001)$. Assault was more frequent in the

\section{Table 1. ASSOCIATION BETWEEN GENDER, TRAUMA MECHANISM, TYPE OF ZYGOMATICO-ORBITAL FRAC- TURE, PRESENCE OF DISLOCATION, AND AGE GROUP}

\begin{tabular}{|c|c|c|c|c|}
\hline & \multicolumn{2}{|c|}{$\begin{array}{l}\text { Geriatric } \\
\text { Patients } \\
(\mathrm{n}=93) \\
\end{array}$} & \multicolumn{2}{|c|}{$\begin{array}{l}\text { Younger } \\
\text { Controls } \\
(n=68)\end{array}$} \\
\hline & $\mathrm{n}$ & $\%$ & $\mathrm{n}$ & $\%$ \\
\hline \multicolumn{5}{|l|}{ Gender } \\
\hline Men & 49 & 52.7 & 61 & 89.7 \\
\hline Women & 44 & 47.3 & 7 & 10.3 \\
\hline \multicolumn{5}{|l|}{$P<.001$} \\
\hline \multicolumn{5}{|l|}{ Trauma mechanism } \\
\hline Ground-level fall & 65 & 69.9 & 8 & 11.8 \\
\hline Bicycle accident & 12 & 12.9 & 7 & 10.3 \\
\hline MVA & 6 & 6.4 & 3 & 4.4 \\
\hline Fall from height & 5 & 5.4 & 4 & 5.9 \\
\hline Assault & 3 & 3.2 & 33 & 48.5 \\
\hline Struck by blunt object & 1 & 1.1 & 3 & 4.4 \\
\hline Unknown & 1 & 1.1 & 0 & 0.0 \\
\hline Sport & 0 & 0.0 & 10 & 14.7 \\
\hline \multicolumn{5}{|l|}{$P<.001$} \\
\hline \multicolumn{5}{|l|}{ Type of ZMO fracture } \\
\hline ZMO with arch fracture & 65 & 69.9 & 46 & 67.6 \\
\hline Isolated arch fracture & 15 & 16.1 & 13 & 19.1 \\
\hline ZMO without arch fracture & 13 & 14.0 & 9 & 13.2 \\
\hline \multicolumn{5}{|l|}{$P=.884$} \\
\hline \multicolumn{5}{|l|}{ ZMO dislocation } \\
\hline Present & 64 & 68.8 & 61 & 89.7 \\
\hline Absent & 29 & 31.2 & 7 & 10.3 \\
\hline$P=.002$ & & & & \\
\hline
\end{tabular}

Abbreviations: MVA, motor vehicle accident; ZMO, zygomatico-orbital.

Toivari et al. Associated Injuries in Geriatric ZMO Fracture. J Oral Maxillofac Surg 2019. control group $(P<.001)$, whereas a ground-level fall was more frequent in the geriatric group $(P<.001)$. Fracture dislocation was significantly more often absent in the geriatric group than in the control group $(P=.004)$.

Table 2 presents the association between gender, trauma mechanism, type of ZMO fracture, ZMO dislocation, and AI outside the face. Significant predictors for AIs were MVA, fall from a height, and absence of fracture dislocation $(P<.001)$.

Table 3 presents the association between outcome variables and predictor variables. AIs outside the face in general $(P<.001)$ and brain injuries in particular $(P<.001)$ were significantly more frequent in the geriatric group than in the control group. The absence of restricted mouth opening and the absence of zygomatic prominence asymmetry were significantly more frequent in the geriatric group $(P<.001)$.

Table 4 presents the $2 \times 2$ risk analysis between the absence of fracture dislocation, presence and severity

Table 2. ASSOCIATION BETWEEN GENDER, TRAUMA MECHANISM, TYPE OF ZYGOMATICO-ORBITAL FRACTURE, AND PRESENCE OF ASSOCIATED INJURY

\begin{tabular}{|c|c|c|c|c|}
\hline & \multicolumn{2}{|c|}{ AI Present } & \multicolumn{2}{|c|}{ AI Absent } \\
\hline & $\mathrm{n}$ & $\%$ & $\mathrm{n}$ & $\%$ \\
\hline Population & 50 & 31.1 & 111 & 68.9 \\
\hline \multicolumn{5}{|l|}{ Gender } \\
\hline Men & 29 & 26.4 & 81 & 73.6 \\
\hline Women & 21 & 41.2 & 30 & 58.8 \\
\hline \multicolumn{5}{|l|}{$P=.059$} \\
\hline \multicolumn{5}{|l|}{ Trauma mechanism } \\
\hline Ground-level fall & 28 & 38.4 & 45 & 61.6 \\
\hline Bicycle accident & 7 & 36.8 & 12 & 63.6 \\
\hline MVA & 6 & 66.7 & 3 & 33.3 \\
\hline Fall from height & 6 & 66.7 & 3 & 33.3 \\
\hline Assault & 1 & 2.8 & 35 & 97.9 \\
\hline Struck by blunt object & 1 & 25.0 & 3 & 75.7 \\
\hline Unknown & 1 & 100.0 & 0 & 0.0 \\
\hline Sport & 0 & 0.0 & 10 & 100.0 \\
\hline \multicolumn{5}{|l|}{$P<.001$} \\
\hline \multicolumn{5}{|l|}{ Type of ZMO fracture } \\
\hline ZMO with arch fracture & 31 & 27.9 & 80 & 72.1 \\
\hline Isolated arch fracture & 11 & 39.3 & 17 & 60.7 \\
\hline ZMO without arch fracture & 8 & 36.4 & 14 & 63.6 \\
\hline \multicolumn{5}{|l|}{$P=.431$} \\
\hline \multicolumn{5}{|l|}{ ZMO dislocation } \\
\hline Present & 28 & 22.6 & 97 & 87.4 \\
\hline Absent & 22 & 59.5 & 14 & 12.6 \\
\hline$P<.001$ & & & & \\
\hline
\end{tabular}

Abbreviations: AI, associated injury; MVA, motor vehicle accident; ZMO, zygomatico-orbital.

Toivari et al. Associated Injuries in Geriatric ZMO Fracture. J Oral Maxillofac Surg 2019. 
Table 3. ASSOCIATION BETWEEN OUTCOME VARIABLES AND AGE GROUP

\begin{tabular}{|c|c|c|c|c|c|}
\hline & \multicolumn{2}{|c|}{$\begin{array}{c}\text { Geriatric Patients } \\
\quad(n=93)\end{array}$} & \multicolumn{2}{|c|}{$\begin{array}{c}\text { Younger Controls } \\
(\mathrm{n}=68)\end{array}$} & \multirow[b]{2}{*}{$P$ Value } \\
\hline & $\mathrm{n}$ & $\%$ & $\mathrm{n}$ & $\%$ & \\
\hline AIs present & & & & & $<.001$ \\
\hline Yes & 40 & 43.0 & 10 & 14.7 & \\
\hline \multicolumn{6}{|l|}{ Types of AI } \\
\hline Brain & 24 & 25.8 & 3 & 4.4 & $<.001$ \\
\hline Extremities & 19 & 20.4 & 9 & 13.2 & .234 \\
\hline Chest & 5 & 5.4 & 5 & 7.4 & .608 \\
\hline Spine & 4 & 4.3 & 1 & 1.5 & .307 \\
\hline Abdomen & 2 & 2.2 & 0 & 0.0 & .224 \\
\hline Carotid artery dissection & 0 & 0.0 & 1 & 1.5 & .241 \\
\hline Severity of AI & & & & & .285 \\
\hline Multiple AIs & 8 & 8.6 & 2 & 2.9 & \\
\hline Polytrauma & 3 & 3.2 & 2 & 2.9 & \\
\hline Mortality & 2 & 2.2 & 0 & 0.0 & \\
\hline Ocular injuries & & & & & .306 \\
\hline Yes & 4 & 4.3 & 1 & 1.5 & \\
\hline $\mathrm{RBH}$ & 1 & & 0 & & \\
\hline Oculus perforation & 1 & & 0 & & \\
\hline Vitreous hemorrhage & 1 & & 0 & & \\
\hline Vitreous detachment & 1 & & 0 & & \\
\hline Corneal erosion & 0 & & 1 & & \\
\hline $\begin{array}{l}\text { Restricted maximal mandible } \\
\text { opening }\end{array}$ & & & & & $<.001$ \\
\hline No restriction & 79 & 84.9 & 43 & 63.2 & \\
\hline Restricted & 9 & 9.7 & 23 & 33.8 & \\
\hline Indifferent & 5 & 5.4 & 2 & 2.9 & \\
\hline Zygomatic buttress asymmetry & & & & & $<.001$ \\
\hline No & 52 & 55.9 & 8 & 11.8 & \\
\hline Yes & 31 & 33.3 & 44 & 64.7 & \\
\hline Indifferent & 10 & 10.8 & 16 & 23.5 & \\
\hline
\end{tabular}

Abbreviations: AI, associated injury; RBH, retrobulbar hematoma.

Toivari et al. Associated Injuries in Geriatric ZMO Fracture. J Oral Maxillofac Surg 2019.

of AIs outside the face, ocular injuries, and primary predictors. The geriatric group had a significantly higher risk of AI outside the face $(P<.001)$, brain injury $(P=.003)$, and absence of dislocation $(P=.003)$. The calculated risks for AI outside the face, brain injury, and absence of dislocation were $2.9,5.8$, and 3.4, respectively.

The logistic regression analysis with 95\% CIs for the presence of brain injury is presented in Table 5. In bivariate analyses, the geriatric group had a 7.5-fold

\section{Table 4. 2 × 2 RISK ANALYSIS BETWEEN ABSENCE OF DISLOCATION IN ZYGOMATICO-ORBITAL FRACTURE, PRESENCE AND SEVERITY OF ASSOCIATED INJURY, OCULAR INJURIES, AND AGE GROUP}

\begin{tabular}{|c|c|c|c|c|c|c|}
\hline & Dislocation Absent & AIs Present & Brain Injury & Multiple AIs & Polytrauma & Ocular Injury \\
\hline Age Group & RR (95\% CI) & RR (95\% CI) & RR (95\% CI) & RR (95\% CI) & RR (95\% CI) & RR $(95 \% \mathrm{CI})$ \\
\hline Geriatric & $3.4(1.4-8.0)$ & $2.9(1.6-5.4)$ & $5.8(1.8-8.6)$ & $2.9(0.6-13.3)$ & $1.1(0.2-6.4)$ & $2.9(0.3-25.6)$ \\
\hline Younger control & ref & ref & ref & ref & ref & ref \\
\hline$P$ value & .003 & $<.001$ & .003 & .166 & .918 & .332 \\
\hline
\end{tabular}

Abbreviations: AI, associated injury; CI, confidence interval; ref, reference; RR, risk ratio.

Toivari et al. Associated Injuries in Geriatric ZMO Fracture. J Oral Maxillofac Surg 2019. 
higher risk of brain injuries compared with the younger control group $(P<.001)$. When adjusted for gender and the presence of fracture dislocation, the risk of brain injury was 5.3-fold higher and the difference remained significant $(P=.012)$. The absence of fracture dislocation caused a 2.5 -fold higher risk of brain injuries when adjusted and compared with the presence of fracture dislocation $(P=.046)$.

Table 6 presents the anatomic AI sites outside the face in the geriatric and control groups in more detail. The commonest $\mathrm{AI}$ in the geriatric group was an upper limb fracture (14 of 93 patients), whereas the most frequent $\mathrm{AI}$ in the control group was a lower limb fracture ( 5 of 68). Brain injuries diagnosed in the geriatric group consisted of SDH (13 of 93), subarachnoidal hematoma (10 of 93), brain contusion (7 of 93), intraparenchymal hematoma ( 3 of 93), and epidural hematoma (2 of 93).

\section{Discussion}

The purpose of the present study was to investigate AIs in geriatric patients with ZMO fractures. The specific aims were to clarify the occurrence of, risk factors for, and types of AI in geriatric patients with ZMO fractures and to compare the occurrence and types of $\mathrm{AI}$ between geriatric patients and younger adult patients. The hypotheses were that AIs are frequent and severe in geriatric patients and that they occur more frequently in geriatric patients than in younger adult patients.

The hypotheses were confirmed. AIs outside the face in general $(P<.001)$, and brain injuries in particular $(P<.001)$, were significantly more frequent in the geriatric group than in the younger control group. The geriatric group had a 2.9-fold higher risk of AI outside the face in general and a 5.8-fold higher risk of brain injury compared with the control group. The absence of fracture dislocation was associated with a 2.5 -fold higher risk of brain injury.

Brain injuries are common in patients with facial trauma; their occurrence varies from 9.9 to $34.0 \%$ among all patients with facial trauma and from 18.8 to $53.9 \%$ among geriatric patients with facial trauma. ${ }^{8-10,14}$ The present results underline the significant relation and the risk of brain injuries associated with ZMO fractures in geriatric patients (25.8\%) compared with younger adult patients (4.4\%; $P<.001)$. The frequency of non-concussive brain trauma in geriatric patients has been explained by the increased usage of anticoagulation and antiplatelet therapy $^{15}$; however, another notable factor is that a sudden head impact combined with age-related brain atrophy predisposes the elderly to sudden brain movement, resulting in a venous tear and particularly in a high frequency of subarachnoidal hematomas in geriatric patients. ${ }^{16}$ According to the results of the present study, SDH was diagnosed as the most common type of brain injury in the geriatric group (14.0\%); the corresponding rate for the control group was $0.0 \%$.

The results of the present study showed that 59.5\% of AIs outside the face were diagnosed in the absence of fracture dislocation. In logistic regression analysis, the absence of ZMO fracture dislocation caused a statistically relevant 2.5 -fold higher risk for the presence of brain injury compared with the presence of dislocation and adjusted for age, gender, and dislocation. This is an important finding of the study, which has not been reported previously.

In addition to the absence of radiologic fracture dislocation, the present results analogously showed that restricted mouth opening and zygomatic buttress

Table 5. LOGISTIC REGRESSION ANALYSIS WITH 95\% CONFIDENCE INTERVALS FOR PRESENCE OF BRAIN INJURY

\begin{tabular}{|c|c|c|c|c|c|c|}
\hline & \multicolumn{3}{|c|}{ Unadjusted } & \multicolumn{3}{|c|}{ Adjusted* } \\
\hline & OR & $95 \% \mathrm{CI}$ & $P$ Value & OR & $95 \% \mathrm{CI}$ & $P$ Value \\
\hline \multicolumn{7}{|l|}{ Age group } \\
\hline Geriatric group & 7.5 & $2.2-26.2$ & .002 & 5.3 & $1.4-19.7$ & .012 \\
\hline Younger control & ref & & & ref & & \\
\hline \multicolumn{7}{|l|}{ Gender } \\
\hline Female & 2.8 & $1.2-6.6$ & .016 & 1.6 & $0.7-4.0$ & .300 \\
\hline Male & - & - & - & ref & & \\
\hline \multicolumn{7}{|l|}{ Dislocation } \\
\hline Absent & 3.5 & $1.5-8.4$ & $<.001$ & 2.5 & $1.0-6.3$ & .046 \\
\hline Present & ref & - & - & ref & & \\
\hline
\end{tabular}

Abbreviations: CI, confidence interval; OR, odds ratio; ref, reference.

* Adjusted for age, gender, and dislocation. 
Table 6. SITE OF ASSOCIATED INJURIES IN GERIATRIC AND YOUNGER ADULT PATIENTS

\begin{tabular}{|c|c|c|c|c|}
\hline \multirow[b]{2}{*}{ Anatomic Site of AI } & \multicolumn{2}{|c|}{$\begin{array}{l}\text { Geriatric } \\
\text { Patients } \\
(n=93)\end{array}$} & \multicolumn{2}{|c|}{$\begin{array}{c}\text { Younger } \\
\text { Controls } \\
(\mathrm{n}=68)\end{array}$} \\
\hline & $\mathrm{n}$ & $\%$ & $\mathrm{n}$ & $\%$ \\
\hline Upper limb fracture & 14 & 15.1 & 1 & 1.5 \\
\hline Subdural hematoma & 13 & 14.0 & 0 & 0.0 \\
\hline Subarachnoidal hematoma & 10 & 10.8 & 0 & 0.0 \\
\hline Brain contusion & 7 & 7.5 & 2 & 2.9 \\
\hline Rib fracture & 5 & 5.4 & 2 & 2.9 \\
\hline Cervical spine injury & 3 & 3.2 & 1 & 1.5 \\
\hline $\begin{array}{l}\text { Intraparenchymal } \\
\text { hematoma }\end{array}$ & 3 & 3.2 & 0 & 0.0 \\
\hline Lower limb fracture & 2 & 2.2 & 5 & 7.4 \\
\hline Epidural hematoma & 2 & 2.2 & 2 & 2.9 \\
\hline Clavicle fracture & 2 & 2.2 & 3 & 4.4 \\
\hline Pelvic fracture & 2 & 2.2 & 1 & 1.5 \\
\hline Kidney rupture & 2 & 2.2 & 0 & 0.0 \\
\hline Pneumothorax & 1 & 1.1 & 1 & 1.5 \\
\hline Scapula fracture & 1 & 1.1 & 1 & 1.5 \\
\hline Thoracic spine injury & 1 & 1.1 & 0 & 0.0 \\
\hline $\begin{array}{l}\text { Upper limb ligament } \\
\text { injury (MCP) }\end{array}$ & 1 & 1.1 & 0 & 0.0 \\
\hline Pulmonary contusion & 0 & 0.0 & 2 & 2.9 \\
\hline $\begin{array}{l}\text { Lower limb ligament } \\
\text { injury (ATFL) }\end{array}$ & 0 & 0.0 & 1 & 1.5 \\
\hline $\begin{array}{l}\text { Carotid artery dissection } \\
\text { (grade II) }\end{array}$ & 0 & 0.0 & 1 & 1.5 \\
\hline
\end{tabular}

Abbreviations: AI, associated injury; ATFL, anterior talofibular ligament; MCP, metacarpophalangeal.

Toivari et al. Associated Injuries in Geriatric ZMO Fracture. J Oral Maxillofac Surg 2019.

asymmetry were absent from the clinical status significantly more frequently in the geriatric group than in the control group $(P<.001)$. Despite the analogy between clinical and radiologic status, the large discrepancy in the registration of clinical asymmetry raises concern over potential underdiagnosis, which has far too commonly been observed, for instance, in trauma triage settings. ${ }^{17-19}$ To avoid underdiagnosis, clinicians also need to be mindful of geriatric facial trauma.

A drawback of this study is its retrospective nature, because a prospective follow-up would have provided the possibility of recognizing milder brain trauma without radiologic findings. The strength of this study is its ability to establish a relation between isolated ZMO fractures and brain injuries in geriatric patients.
Geriatric patients with ZMO fractures have an increased odds ratio of AIs in general and brain injuries in particular. Clinicians should actively exclude brain injuries in geriatric patients, even in those cases in which no dislocation of the zygoma is clinically present. The re-evaluation of triage parameters in geriatric facial trauma is recommended.

\section{References}

1. Boffano P, Roccia F, Zavattero E, et al: European Maxillofacial Trauma (EURMAT) project: A multicenter and prospective study. J Craniomaxillofac Surg 43:62, 2015

2. Adam AA, Zhi L, Bing LZ, Zhong Xhing WU: Evaluation of treatment of zygomatic bone and zygomatic arch fractures: A retrospective study of 10 years. J Maxillofac Oral Surg 11:171, 2012

3. Blumer M, Kumalic S, Gander T, et al: Retrospective analysis of 471 surgically treated zygomaticomaxillary complex fractures. J Craniomaxillofac Surg 46:269, 2018

4. Ellis E, El-Tattar A, Moos UF: An analysis of 2,067 cases of zygomatico-orbital fracture. J Oral Maxillofac Surg 43:417, 1985

5. Bogusiak K, Arkuszewski P: Characteristics and epidemiology of zygomaticomaxillary complex fractures. J Craniofac Surg 21: 1018,2010

6. Royan SJ, Hamid AL, Kovilpillai FJ, et al: A prospective study on elderly patients with facial fractures in a developing country. Gerontology 25:124, 2008

7. Gerbino G, Roccia F, De Gioanni PP, Berrone S: Maxillofacial trauma in the elderly. J Oral Maxillofac Surg 57:777, 1999

8. Kloss FR, Tuli T, Häckl O, et al: The impact of ageing on craniomaxillofacial trauma-A comparative investigation. Int J Oral Maxillofac Surg 36:1158, 2007

9. Toivari M, Suominen AL, Lindqvist C, Thorén H: Among patients with facial fractures, geriatric patients have increased risk for associated injuries. J Oral Maxillofac Surg 74:1403, 2016

10. Clavijo-Alvarez JA, Dleyiannis FWB, Peitzman AB, Zenati MS: Risk factors for death in elderly patients with facial fractures secondary to falls. J Craniofac Surg 23:494, 2012

11. Hohlrieder M, Hinterhoelzl J, Ulmer H, et al: Maxillofacial fractures masking traumatic intracranial hemorrhages. Int J Maxillofac Surg 33:389, 2004

12. Patil SG, Patil BS, Joshi U, et al: The facial skeleton: Armor to the brain? Indian J Dent 7:116, 2016

13. Ramneesh G, Gulzar G, Sanjeev U, et al: A retrospective audit of hundred patients of orbitozygomatic fractures with brain injury. J Clin Diagn Res 8:NC04, 2014

14. Schumate R, Portnof J, Amundson M, et al: Recommendations for care of geriatric maxillofacial trauma patients following a retrospective multicenter review. Oral Maxillofac Surg 26(1), 2017

15. Harvey LA, Close JCT: Traumatic spine injuries in older adults: Characteristics, causes and consequences. Injury 43:1821, 2012

16. Winn HR: Youmans Neurological Surgery E-Book; 2014. New York, Elsevier, 2014. Available at: https://ebookcentral-proquest-com. liproxy.helsinki.fi/lib/helsinki-ebooks/detal.action?docID=1430015

17. Rogers A, Rogers F, Bradbrusn W, et al: Old and undertriaged: A lethal combination. Am Surg 78:711, 2012

18. Garve T, Stewart K, Stoner J, et al: Out-of-hospital and interhospital under-triage to designated tertiary trauma centers among injured older adults. A 10-year statewide geospatialadjusted analysis. Prehosp Emerg Care 23:737, 2017

19. Reske-Nielsen C, Medzon R: Geriatric trauma. Emerg Med Clin North Am 34:483, 2016 